UMR. and ind

ASIRPA: A COMPREHENSIVE THEORY-BASED APPROACH TO ASSESSING THE SOCIETAL

IMPACTS OF A RESEARCH ORGANIZATION

JOLY Pierre-Benoît ; GAUNAND Ariane ; COLINET Laurence ; LAREDO Philippe ;

LEMARIE Stéphane ; MATT Mireille

- March 2015 -

JEL CODES : H43 ; 033 ; A13

Working Paper GAEL ; 2015-04 


\title{
ASIRPA: A comprehensive theory-based approach to assessing the societal impacts of a research organization
}

\author{
P.-B. Joly $\left({ }^{1, \mu}\right)$, A. Gaunand $\left({ }^{2,3}\right)$, L. Colinet $\left({ }^{4}\right)$, P. Larédo $\left({ }^{5}\right)$, S. Lemarié $\left({ }^{2,3}\right)$, M. Matt $\left({ }^{2,3}\right)$
}

${ }^{1}$ Université Paris Est, LISIS, UMR 1326 INRA- Champs sur Marne 77454 Marne-la-Vallée Cedex 2

${ }^{2}$ INRA, UMR1215 GAEL, F-38000 Grenoble, France

${ }^{3}$ Univ. Grenoble Alpes, UMR 1215 GAEL, F- 38000 Grenoble, France

${ }^{4}$ Directorate College - INRA Department head - 147 rue de l’Université, 75338 Paris Cedex 07

${ }^{5}$ Université Paris Est, LISIS, Ecole des Ponts et Chaussées- Champs sur Marne 77454 Marne-la-Vallée Cedex 2,

$\mu$ : corresponding author: joly@inra-ifris.org

$\underline{\text { Abstract: }}$

ASIRPA is an original and comprehensive approach for assessing the socio-economic impact of PROs through case studies. The cases are theory-based, selected to characterize the diversity of the broader impacts, and standardized so as to allow the scaling-up of the analysis of impact to the level of the organization. ASIRPA is founded on well-tried tools and the added-value of the approach lies in the adaptation and combination of these tools to design a comprehensive approach, which has been tested in a real situation and proven to be robust, credible, and implementable.

$\underline{\text { Keywords: }}$

societal impacts; comprehensive assessment approach; impact pathway; agricultural research; Public Research Organisation

JEL codes:

H43, O33, A13 


\section{Funding:}

This work was supported by the French National Agricultural Research Institute (INRA), who funded the ASIRPA project

\section{Acknowledgments}

We thank the numerous people who contributed directly and indirectly. Special mention goes to the members of the project's scientific committee whose contribution was crucial: Irwin Feller (Committee Chair), Barry Bozeman, Christiane Deslauriers, Jeremy Foltz, Luke Geoghiou, and Huub Loffer.

\section{Introduction}

Research Impact Assessment (RIA) is not a new issue; since the 1950s, the economic returns to research investment have been analyzed repeatedly. In addition, major programmes based on case studies (such as TRACES and HINDSIGHT) have focused on analysis of the nonacademic impact of research. However, RIA is receiving renewed attention in light of increased expectations about the ability of research to deliver socio-economic impacts. The Lisbon Agenda (2001) is one of the landmarks in this evolution, and the organization of research towards Grand challenges has extended this logic. This context is promoting a revival of interest in RIA methodologies, and has been the motivation for a number of projects such as: Assessments of the impacts of the Advanced Technology Program (ATP) (Ruegg \& Feller 2003), Public Value Mapping (Bozeman 2003), the Payback Framework (Donovan \& Hanney 2011), and the Social Impact Assessment Method (SIAMPI) (Spaapen \& Van Drooge 2011). Various institutions have designed and are experimenting with new ways to assess the impacts of their research. Public sector Research Organizations (PROs) dedicated to agriculture are contributing to this rich field of experimentation including the 
Consultative Group for International Agricultural Research or CGIAR (Walker et al. 2008), EMBRAPA the Brazilian corporation of agricultural research (2013), and Commonwealth Scientific and Industrial Research Organisation or CSIRO for Australian research (Acil Tasman Pty Ltd 2010)). However, there is no international methodological standard for assessing societal impact. Without efforts to establish a standard, simplistic metrics will prevail and will discourage research on strongly desirable societal objectives (Ernø-Kjølhede \& Hansson 2011).

In this context, the ASIRPA project (Socio-Economic Analysis of the Impacts of Public Agricultural Research) was launched by the French National Agricultural Research Institute (INRA) in 2011. ASIRPA is an ex-post research impact assessment approach based on standardized case studies and aimed at internal learning and accountability. Unlike 'traditional case studies' which provide rich story-telling but little explanation of impact mechanisms (Bozeman and Kingsley 1997), our cases are based on a theory of impact that is inspired by innovation studies, more specifically, the theory of translation -or Actor Network Theory (Callon 1986). Scholars agree that the innovation process draws on the involvement of heterogeneous actors which play complementary roles and transform knowledge through a series of steps on the path to innovation. Innovation draws on the extension of technoeconomic networks (Callon 1992), it is both social and technical (Bijker 1995), and it is distributed (Green et al. 1999) and open (Chesbrough 2006). All these theories have a common belief that scientific knowledge as such is not useful but is made useful through a series of transformations performed by different actors. Thus, our theory of the impact of research is different from predictions based on the traditional theory of production (see Griliches (1958) for a seminal contribution) which seeks to measure the marginal productivity of knowledge. The ASIRPA approach pays attention to the process of transformation which renders knowledge actionable by incorporating it into new products, processes, and ways of 
doing or governing things. This means that an impact analysis has to go beyond mere identification of inputs and outputs, and identify the chain of translations that occur in the process.

Our approach is part of the broader impact literature that considers the diversity of societal impacts, the contribution of networks of actors to the innovation process, and the scaling-up possibilities from individual case studies to a global picture of impact. Some studies refer to the evaluation of R\&D programs (Nason et al. 2011), research centers (Molas-Gallart \& Tang 2011), and PROs (Campbell et al. 2010; Walker et al. 2008). All of them take account of the variety of impacts, and the role of multiple actors in the impact generating processes. ASIRPA is also close to the SIAMPI method (Spaapen \& Van Drooge 2011) which suggests substituting contribution and productive interactions for the traditional attributions in research impact assessments. Thus, belongs to the family of approaches that investigate impact generating mechanisms, disentangle the roles of networks of actors in the innovation process, bypass project fallacy pitfalls (Georghiou et al. 2002), and account for long term impacts. As a comprehensive approach, ASIRPA also offers some solutions to aggregate case study results at the level of the organization.

In the remaining part of the paper, first we review the main issues addressed in the literature on broader impact assessment (section 2). Based on these key conceptual issues, we then discuss the characteristics of ASIRPA (section 3). Section 4 discusses the power of that approach to overcome some of the limitations of earlier work, and provides some insights into its applicability to PROs based on feedback from six INRA research departments. 


\section{Literature review: the foundations of a new approach to research impact assessment}

There are three key elements that can be identified in the recent literature on RIA. First, there is wide agreement on the need to go beyond economic impact and to assess the 'broader impacts'. As discussed in a Special Issue of Research Evaluation (September 2011) attention has been devoted to societal impact (or the broader impacts) of publicly funded research. Second, (probably less widely agreed) is the renewal of innovation theory and the focus on the mechanisms that produce an impact in order to find ways to improve them. Thus, RIA is concerned not just with accountability; it is foremost a tool for learning. The third element is essentially methodological: most RIA methodologies are based on case studies which has led to discussion of the benefits and limitations of such methodologies, and ways to improve them.

\subsection{How to take into account and measure the diversity of the impacts of research?}

The diverse terms used to describe broader impact - : third stream activities, societal benefits, societal quality, usefulness, public values, knowledge transfer and societal relevance - are a sign of the intensity of the efforts being made to go beyond scientific and economic impacts (Bornmann 2013). Although most studies of RIA focus on economic impacts (Donovan and Hanney 2011; Georghiou \& Roesner 2000; Salter \& Martin 2001; Bozeman \& Melkers 1993; Ruegg \& Feller 2003), other dimensions are attracting increasing attention. They include:

- environmental impact (Georghiou \& Bach 1998; Donovan 2011; Hermann et al. 2006; Walker et al. 2008);

- social impact (Donovan 2011; Bozeman 2003; Ruegg \& Feller 2003; Molas-Gallart \& Tang 2011) ; 
- political impact (Donovan and Hanney, 2011; Bell et al. 2011);

- cultural impact (Bornmann 2013, Godin \& Doré 2005);

- organizational impact (Godin \& Doré 2005);

- impact on health (Donovan and Hanney 2011; Bozeman 2003).

Most of these papers propose useful methodologies to take account of diverse dimensions of socio-economic impact. Assessment of the ATP program has provided the opportunity to test many of these methodologies (Ruegg \& Feller 2003). The problem is not lack of methods but rather as Bornmann (2013, p. 219) suggests, lack of 'an accepted framework with adequate data sets, criteria, and methods for the evaluation of societal impact'. For each dimension, the literature proposes a multiplicity of indicators (Bornmann (2013) identifies more than 60). In the context of case studies, the challenge is to take advantage of local, idiosyncratic measures, and to suggest indicators that are acceptable to a wide audience. To discuss this issue we focus on two approaches that are deliberately multidimensional: the Payback Framework, and the Public Value Mapping (PVM) approach.

The Payback Framework (Donovan \& Hanney 2011) was created to assess the outcomes of health research structures. It consists of a logic model of the research processes, and various categories of research paybacks and anticipated impacts. Various types of benefits are considered: academic benefits (publications, research reports, etc.), benefits to future research (development of research skills), benefits from informing policy and product development (improved information bases for political decisions, development of pharmaceutical products), health and health sector benefits (improved health, improved equity in service delivery), and broader economic benefits. The Payback Framework has been applied in various contexts within and outside the health area, for instance in National Breast Cancer Foundation-funded research based on 16 case studies (Donovan et al. 2014). This approach has two main limitations. First, in relation to non-academic benefits, the impact measures are 
qualitative and ad hoc which hampers aggregation within (various impact dimensions) and among case studies, and generalization of results. Second, this approach is limited to analysis of research programs and research projects and is not suited to PROs.

Public Value Mapping was proposed in the early 2000s by Bozeman and Sarewitz (Bozeman 2003; Bozeman \& Sarewitz 2011). It challenges traditional rationales for public funding of research based on the argument of market failure because of the public good characteristic of science (Arrow 1962; Nelson 1959). Against this background, Bozeman and Sarewitz propose an approach to assess what they call 'public values' of science, i.e. non-scientific, noneconomic goals of research. Public values encompass outcomes such as environmental quality, environmental sustainability, health care, and provision of basic needs, e.g. housing and food. In the PVM approach, the different dimensions of impacts (the set of public values) are not defined a priori. They are contingent on the goals of a program or a given organization. Hence, the core of the PVM consists (i) of identifying research goals and objectives (sources are legislation, mission statements, strategic plans, etc.) and (ii) of analyzing the procedural and logical connections between them, and the identifiable societal outcomes. Better articulated formulation of goals and assessment of outcomes in order to prevent public failures are crucial. However, the contingency of the dimensions of impacts makes it impossible to aggregate (and difficult to compare) them, and prevents the approach from contributing to an elaboration of generic metrics.

Hence, although the issue of assessing the broader impacts of research is high on the policy agenda, and although a number of methodologies for measuring different dimensions of impact is available, current approaches do not provide a generic metric for each of the main dimensions of impact, or the resources for producing it. Indeed, generic metrics are available for scientific and economic impact, and to a lesser extent health impact (Kamenetzky 2013). 
For the other dimensions (environment, public policy, social) we are reliant on ad hoc measures. This is an important shortcoming which we try to address.

\subsection{Understanding the mechanisms}

Traditional methodologies disregard the upstream mechanisms generating research impact since they consider that 'good things' will happen from quality research through a linear model of innovation (Bozeman 2003, p. 20). Hence they concentrate on analysis of the relations between inputs and outputs. These analyses, grounded in the traditional theory of production (Cf. Griliches 1958), focus on causality and attribution: how strong is the link between an observed change and a given research investment? What part of this change can be attributed to a given research investment? In this framework, knowledge is considered as a means of production, along with labor and capital; the main issue then is to measure the marginal productivity of knowledge in order to be able to compute the return on investment (ROI).

Recent approaches challenge this traditional perspective and open the black box of impact generating mechanisms. In the Public Value Mapping approach, scientific knowledge gains value through its use by 'Knowledge Value Collective' (KVC) actors, 'for example, government and private funding agents, end users, wholesalers, equipment and other scientific resource vendors, and so forth' (Bozeman 2003, p. 13). KVC 'move[s] science from an individual and small group enterprise, to knowledge development and dissemination' through the whole of society, 'ultimately, [producing] social outcome[s]' (Bozeman 2003, p. 27). It is necessary to focus not on a single actor but on the dynamics of the broadest social group. For Bozeman and Sarewitz (2011, p. 19), the following factors which are also considered analytical lenses, are mobilized to analyze the social impacts of research: the characteristics of the knowledge that the research produces, the institutional arrangements and management 
affecting knowledge production and use (user-producer interactions, networking,..), and policy and political domains of knowledge production and use (political and legal context such as Intellectual Property Rights). They argue that it is vital to have a deeper understanding of these factors in order to help science policy-makers in 'making choices among competing paths to desired social outcomes’ (Bozeman \& Sarewitz 2011).

The Payback Framework (Donovan 2011) is based on a logic model consisting of stages and interfaces between the research system and the wider user environment. It enables analysis of the 'story' of an innovation from topic identification, project specification, research process, and primary outputs of the research, to the various dissemination steps until final outcomes. The dissemination and adoption phases tend to highlight the role played by intermediaries and beneficiaries.

Two additional sources were instrumental in the design of our proposed approach. The Consultative Group for International Agricultural Research (CGIAR), which has long experience of implementing RIA, has developed a method based on systematic analysis of the Research-to-Impact Pathway (called the 'Impact Pathway') (Douthwaite et al. 2003; Walker et al. 2008). The method draws on the identification of the different phases of impact generation, the actors involved, the flow of resources, and the progressive transformation of knowledge in outcomes and impacts. Although the method might seem based on the traditional linear model, it is not. Networks of stakeholders can play dominant roles in the construction of research outputs as well as in the diffusion and adoption processes at multiscale levels. The method rightly identifies the crucial importance of the scaling up and scaling out processes: technological change is brought about by the formation and actions of networks of stakeholders in what essentially is a social process of communication and negotiation. As a consequence of the complexity of that innovation process, several authors (Douthwaite et al. 2003; Kuby 1999) point to the 'attribution gap' between the project's direct benefits and its 
developmental outcomes. The simplified approach to impact pathway argues that 'a description of who did what and when should be sufficient to let readers decide on the merits of the argument for attribution’ (Walker et al. 2008, p. 45).

The SIAMPI approach (Social Impact Assessment Methods for research and funding instruments through the study of Productive Interactions between science and society) considers the 'productive interactions' between researchers and stakeholders as central to creating research with any kind of impact (Spaapen \& Van Drooge 2011). SIAMPI focuses on the interactions among actors that help produce relevant knowledge, its appropriation, diffusion, and application. Productive interactions are defined as exchanges between researchers and stakeholders (industry, public organizations, government, and the general public) involved in achieving societal impacts. The interaction becomes productive because stakeholders make efforts to use and apply the research results to generate impact. Interactions might be direct (personal links between researchers and stakeholders may accelerate research uptake) or indirect via information carriers (publications, patents). The dynamics of interactions with stakeholders is very context and field specific. Interactions are complex given the evolution of network structure, and the diversity of actors, research fields, and sectors. De Jong et al. (2014) argue that interactions among stakeholders are necessary requirements for research to produce societal impact. Productive interactions may be considered predictors of the success of social outcomes generated. Hence, Spaapen and Van Drooge (2011, p. 212) justify a lack of focus on impacts as such since 'there is not always a clear distinction between social impact and 'productive interactions' because the transition from interaction to impact is often gradual'.

Together with other approaches, SIAMPI claims that it is necessary to shift from attribution to contribution analysis. This is a key element that needs some explanation. Attribution is commonly used both to identify causal relations and to estimate quantitatively how much of 
an observed impact is due to the intervention of a given organization. Attribution supposes that the different causes that produce a given effect are additive, which contradicts what is observed in complex ecosystems of innovation, namely the key importance of synergistic (non additive) interactions. Therefore, attribution may usefully be replaced by a contribution approach. The question then becomes: 'in light of the multiple factors influencing a result, has the intervention made a noticeable contribution to an observed result and in what way?' (Mayne 2012, p. 273). The SIAMPI approach suggests that through detailed analysis of the roles of actors in the process of impact generation, it is possible to identify the contributions made. The authors argue that 'by focusing on 'productive interactions', we shift the focus from attribution and impact to the contribution of specific actors, productive interactions and the exchange of knowledge and expertise by the various stakeholders' (Spaapen \& Van Drooge 2011, p. 215) ${ }^{1}$

Thus it seems clear that recent approaches propose innovative insights on impact generating mechanisms, and offer a number of tools and concepts that contribute to the renewal of RIA: impact pathway, knowledge value concepts, productive interactions, contribution. The key point is that opening the black box of impact provides knowledge to overcome the traditional problem of impact attribution. However, these approaches do not provide information on impact type and size.

We consider that understanding impact mechanisms is not a substitute but rather is complementary to the measure of diversity and amplitude of impact. This is a key challenge for the ASIRPA approach.

\footnotetext{
${ }^{1}$ For a wider discussion of contribution analysis, Cf.: Evaluation, Special Issue: Contribution analysis. July 2012, 18 (3)
} 


\subsection{Issues related to case-study based approaches to broader impact}

All the approaches mentioned above rely on case studies, a very frequent method for RIA (Ruegg \& Jordan 2007). Despite their potential pitfalls (lack of objectivity, quantification, reproducibility), case studies are favored because they offer engagement 'with complexity [and offer] a detailed, in-depth understandings (...) about the description of events or initiatives over which the researcher has little or no control' (Bell et al. 2011, p. 228). They shed light on the translation mechanisms underpinning the innovation process while recognizing its non-linearity and complexity. Studying these mechanisms requires a focus on successes for which societal impact can be observed and whose generation can be backward studied. However, so far, the approaches available generally remain very qualitative and context related. The main challenge for impact evaluation then is to retain the advantages of case studies while reducing their limitations. This is a central objective of our approach which we claim, may be achieved using a standardized approach that combines qualitative and quantitative methodologies.

Also, as several authors point out (Cunningham et al. 2013; Georghiou 1999; Molas-Gallart et al. 2002; Maredia \& Raitzer 2006 for agricultural research), the distribution of impacts is highly skewed. Scherer and Harhoff (2000, p. 562) note that 'researchers who seek to assess the success of government technology programs should focus most of their effort on measuring returns from the relatively few projects with clearly superior payoffs'. This means that ex post assessment allows concentration on a limited number of cases. The case selection process becomes crucial in the case of scaling-up, i.e. accounting for the impact of a PRO through an analysis based on cases. The literature offers few insights on that topic. The rationale for purposive selection of cases is often stratified sampling and at best includes cases with expected high impacts or conducted by researchers with a high impact factor (Hanney et al. 2004). There are few attempts to achieve a balance in researchers' qualifications, modes of 
funding (Hanney et al. 2004), payback categories (Donovan 2011), types of technology (Bozeman \& Kingsley 1997), or scientific disciplines. No methodology has been developed to allow the selection of cases according to the impact patterns involved, and which are representative of a PRO’s overall impact.

There is an urgent need for the integration of these issues in an overarching architecture, and to provide standardized ways to exploit these concepts and tools to achieve a better understanding of societal impact generation. Our approach is a step in this direction.

\section{The ASIRPA approach to assessment of INRA's societal impact}

The ASIRPA approach is consistent with the state of the art described above. It is based on qualitative case studies including relevant quantification of impacts (Donovan 2011), and developed after tailor-made 'theory-based models depicting the flow of impacts from projects’ (Bozeman \& Kingsley 1997, p. 37-38). Compared to 'traditional case studies' described by Bozeman and Kingsley (1997) constituted by story-telling which provide few systematic explanations of impact mechanisms, our cases are based on the hypothesis of the mechanisms generating impacts. Following our literature review, we assume that the impact of research is: i) multidimensional; ii) based on the involvement of networks of actors, iii) at different stages and playing a variety of roles, and vi) over a non-linear impact pathway.

The originality of our approach lies in its comprehensiveness: it offers a complete method for the assessment of the societal impact of a PRO, from the design of a case selection process (section 3.1) to scaling-up to the level of the organization (section 3.3). Standardization of cases is described in section 3.2; it allows comparison and aggregation of data through the creation of a database, and ensures the reproducibility of our approach. 


\subsection{The case selection process}

In order to observe every stage in the innovation process from the start of the research to the societal impacts, we chose only successful cases, as common in the literature (Bornmann 2013, Spaapen \& Van Drooge 2011). Assuming strong asymmetry of socio-economic impacts of research activities (see section 2), the first challenge for ASIRPA is to identify successes at INRA.

For that purpose we used a database that includes a thousand salient research results from INRA laboratories for the period 1996 to 2011 (Gaunand et al. 2015). This database provides an exhaustive list of INRA's potentially successful outputs, and enables a balanced selection of cases related to INRA's activities. To ensure selection of high impact cases we applied various other selection criteria. In addition to being representative of the diversity of INRA's missions and research activities, we required our cases to show high impact and to be based on excellent and recent science (as recommended by the British Research Evaluation Framework (2011): the most recent scientific paper had been published less than 15 years earlier(Research Evaluation Framework 2011). In response to our methodological concern, we searched for cases with impacts on several dimensions (economic, environmental, political, health, social) through a diversity of translation mechanisms.

To confirm our choices, we discussed the salient research results extracted from our database with the 14 heads of INRA's scientific divisions. This resulted in the selection of 33 high impact cases. This number of cases is recommended by several authors and emphasized by Bozeman and Kingsley (1997) as the minimum required for quantitative analysis.

\subsection{Standardized case studies}

After a non-biased selection process, the standardization (Donovan 2011) and 'the quantification of elements across cases' (Bozeman \& Kingsley 1997), became the 
cornerstones for the generalization of results. By standardization we mean the identification and systematic analysis of common features across cases carried out with the same three analytical tools.

\subsubsection{The chronology}

Our chronological analysis highlights the long time, multi-actor and contextual dimensions of impact. It is particularly useful to shed light on the main events in INRA's activities, the creation of outputs, and the turning points in the external context of action. The main events and turning points can relate to the creation of a stock of human capacity, facilities, and resources accumulated by INRA, knowledge and synergies in the 'skills infrastructure' (Nightingale 2004, p1264) built over the long run with a network of partners, the influence of the knowledge pool, etc. That contextual analysis gives an estimate of INRA's inputs, and the connection between these investment phases and the research results. The drawing of the chronology is progressive along the case investigation, since the cases are not projects that come with initially well-defined perimeters (events that are to be included to explain impact are identified all along the case investigation). The start date for the chronology can either be a contribution made by INRA or a contextual event.

Chronology feeds our contribution analysis and helps avoid the project fallacy (Georghiou et al. 2002; Georghiou \& Clarisse 2006). Fallacy relates to funders' expectations to attribute all the effects arising from the related contract whereas the contract is usually one contribution for larger and longer running projects. Project fallacy is accentuated by the diversity of funding sources, and the long lag between funding and impact. Georghiou et al. (2002 p. 261) suggest that methodological improvement are required in relation to project fallacy issues, notably 'a better explanations of the means used by each evaluation approach in order to solve the attribution problem'. The literature generally accepts the idea that the time-lag between 
the research and materialization of its impacts can be very long (from several years for the CGIAR (Douthwaite et al. 2003) to over 30 years for Alston et al. (2009), Poppe (2008), Buxton (2011)). To resolve these issues, most literature methodologies for broader impact assessment, assess intermediate outcomes or anticipated impacts (Donovan et al. 2014) rather than quantifying ex-post observable societal impacts. Because of this temporality, ASIRPA chronology (Figure 1) is not limited to the steps just before the transfer of outputs. Instead, it accounts for all essential events in the path toward impacts.

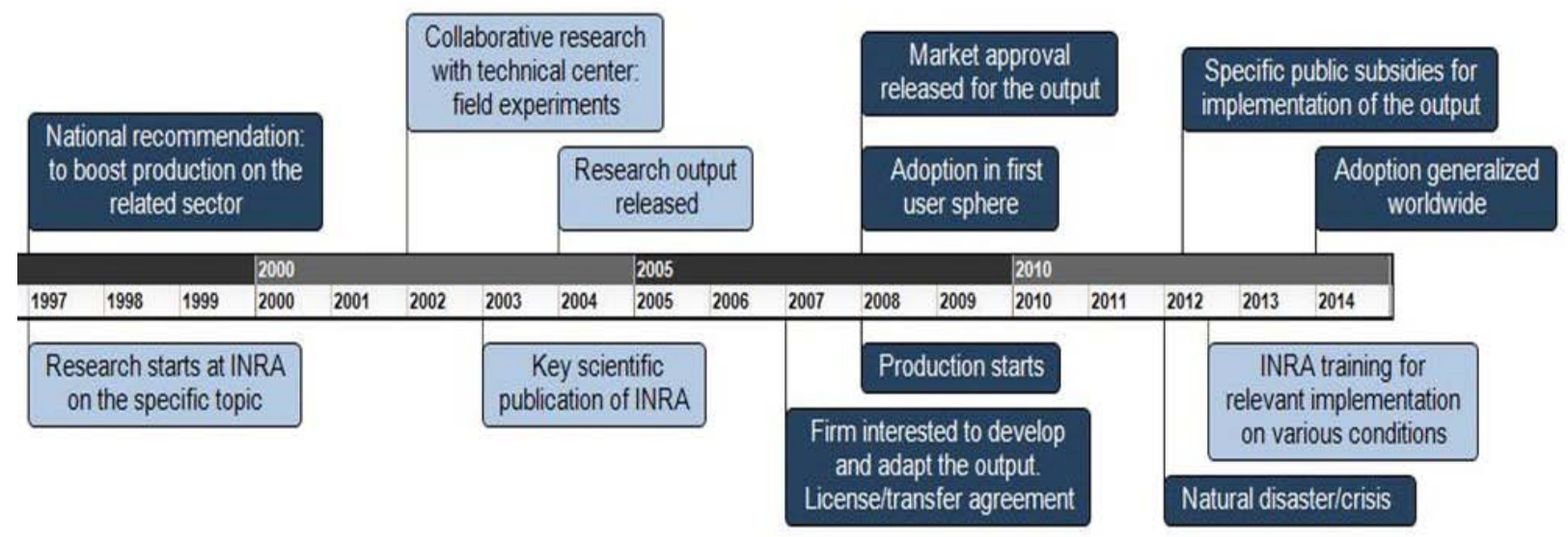

\section{Other events (context...)}

\subsubsection{The Impact Pathway}

ASIRPA's impact pathway offers a graphical representation of the impact-generation steps, highlighting the research work, the knowledge path outside the academic sphere, and its processing and use by socio-economic actors. It captures the diversity of paths and iteration processes while standardizing description of the pathway within a limited number of identifiable phases.

Our impact pathway is adapted from that used for CGIAR (Douthwaite et al. 2003; Walker et al. 2008, see section 2). We enriched our pathway analysis with information related to 
productive configurations, and using the concept of contribution to indicate that impact is produced by the network and cannot be broken down into the contributions of different actors. Nonetheless, the concept of translation is much richer than the concept of interactions since it points to the transformation of the actors involved in the process and the (possible) stabilization of new heterogeneous networks. The notion of impact-generating mechanisms focuses on the involvement of actors in the innovation process through the co-definition of their interests, and the technology. This vision is inspired by actor network theory which defines translation as a four stage process of: (i) defining a common problem which has to be solved (problematization); (ii) interesting and involving the actors (interessement); (iii) defining the roles of the various actors involved (enrolment); and (iv) going beyond the first set of actors (mobilization) (Callon 1986). We thus designed a simple impact pathway to describe the translation mechanisms and to collect the relevant data. There are many translations operations along the impact pathway. For instance, the role of external partners upstream in the problem-setting or knowledge-producing phases, and downstream for the transformation of outputs into impacts.

In contrast to the classical impact pathway (Walker et al. 2008), we integrated three analytical concepts derived from translation theory:

- Productive configuration which encompasses all the financial, human, and physical investments made by INRA and its academic or socio-economic partners for the production of scientific and technological knowledge. We added details regarding the interactions within the networks of actors involved in the inputs, including INRA, which arise from a series of translations. We also analyzed the influence of the epistemic community, and the 'knowledge pools’ (Nedeva 2013) surrounding INRA research in our definition of product configuration.

- Intermediaries operating in different worlds that play key roles for making the knowledge useable. Intermediaries may be organizations dedicated to knowledge transfer 
(extension services, start-ups, regulatory institutions), or objects that incorporate knowledge (technical devices, training facilities). Their roles have been emphasized by many authors, including Colinet et al. (2013) and Klerkx \& Aarts (2013). Recognizing the predominant role of intermediary actors is informative about the potential barriers that hinder impact generation. Intermediaries can emerge from the networks of actors already involved in the input phase, or become involved at a later stage in the impact pathway. They can be preexisting or be created within the process. The detailed analysis of actor networks at the input and intermediaries stages enables us to observe the transformation of networks over time, along the impact pathway. That dynamics is related closely to translation mechanisms. The impact pathway is a key instrument for determining the specific contribution of INRA within these networks.

- The generalization of impacts: the Iceberg Model proposed by Georghiou (2007, p. 747) suggests the need to consider generalization since 'many effects are hidden from superficial observation'. It is the process shifting further than the first sphere of targeted endusers (which we call impacts 1 but can be referred to as intermediate impacts or outcomes in the literature) to wider sets of end-users (which we call impacts 2, and some authors describe as impacts or ultimate impacts). Impacts 2 are enabled by changes in adoption scale, in the diversity of effects, or in learning processes. They may result in a horizontal scaling-up with a greater number of initial end-users being enrolled in a larger spatial area, or in a vertical scaling-up with a greater variety of end-users being enrolled. Thus, it is close to the mobilization concept in translation theory. Some authors such as Maredia and Raitzer (2012) detail other steps in impact diffusion (adoption, effects on targeted beneficiaries, macro effects) which we find relevant in our case.

Iterative and learning processes between the different steps on the pathway are allowed in ASIRPA's non-linear impact pathway representation. In accordance with the literature, the 
ASIRPA methodology also emphasizes the influence of the broader context (scientific, regulatory, economic) at each step on the impact pathway. Considering INRA as a targeted research institute working in three domains (agriculture, food, environment) in partnership with very different sets of actors, and pursuing various missions, the analysis of context is particularly relevant to the ASIRPA approach. The context proved to be singular in the different case studies and requires controls to allow the scaling-up analysis.

Basically, the impact pathway sheds lights on some key points highlighted in the literature, regarding the transformation of research investments into societal impacts: the role of networks of actors, the importance of context, the two spheres of impacts on end-users, and the diversity of the impact dimensions affected. Detailed analysis of the productive configuration and intermediaries addresses some of the limitations of project fallacy, and documents the contribution analysis. As emphasized in the literature review, case study methodology enables us to document the roles of INRA and its partners in terms of their qualitative (and quantitative) contributions along the innovation process toward impacts. Visual representation of the impact pathway summarizes the information collected through interviews.

However, ASIRPA's approach does not assume that the characteristics of interaction processes between researchers and societal stakeholders 'can be used as a proxy for societal impact' (de Jong et al. 2014, p. 90). We consider instead that this link needs thorough analysis through investigation of the mechanisms of translation occurring at the productive configuration stage and also at the intermediary stage, and that impact characterization requires specific efforts. 
For each case, an impact pathway is depicted (see figure 2 for an illustration) making apparent the characteristics of the research (or inputs), its products (outputs), the intermediaries involved, the primary impacts (impacts 1) and the secondary impacts (impacts 2).

Figure 2 : the ASIRPA's impact pathway

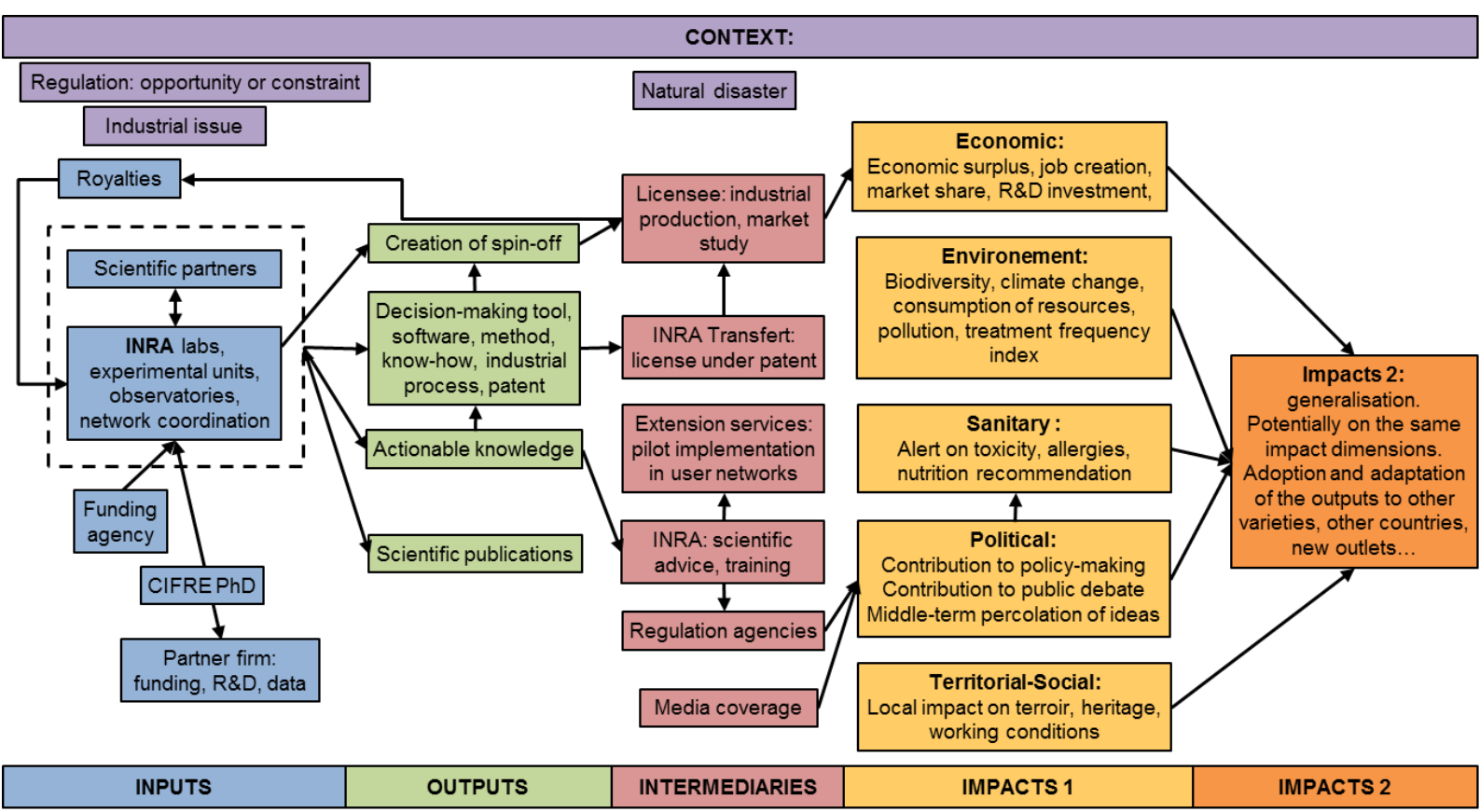

The standardized template of case study reports is based on these five steps on the impact pathway. The impact pathway is the master plan guiding the analysis and data collection for a cross-cutting analysis of cases.

\subsubsection{Qualification and quantification: the vector of impact}

Taking account of the specificities of INRA, we define five dimensions of societal impact. Some of these dimensions are usual for public, mission oriented research organizations: economic, environmental, social, health, and political impacts. However, there are some differences in their definition. Political impact is considered by Bornmann (2013) to be a part of social impact since it contributes to the social capital of a nation; however, we distinguish political impacts since contributing to public debate and influencing policy-making (through policy formulation, empowerment or assessment) are distinct missions of PROs. Our 
definition of social impact includes effects related to the distribution of revenue, and some cultural aspects often accounted for in the literature (see Bornmann 2013 for a review). Health impacts are particularly relevant for INRA since they relate to some specificities of the agricultural sector such as avoidance of sanitary crises, food safety, and nutritional issues. Economic impacts relate to social welfare generation, and environmental impacts relate to effects on pollution, biodiversity, the use of natural resources, and climate change. To these classical dimensions, we add territorial impacts. Impact on territories, investigated by Pascucci and de-Magistris (2011) and Suh and MacPherson (2007) is important for agricultural research because of the need to adapt to local conditions. Furthermore, territories in agriculture represent groups of actors with a common interest in the locally valorized heritage, landscape, terroir (e.g., Geographical Indication labeling).

In order to qualify impacts, descriptors were collected in interviews with stakeholders, for each 'professional adhocracy field' (de Jong et al. 2014, p. 91) related to a case study, and for each dimension of impact. The descriptors are local, embedded in the story of the case, and tailored by stakeholders to account for their activities. These descriptors can relate to qualitative effects or may be statistical indicators. Based on the descriptors we collected, we built indicators specific to each impact dimension but valid for all case studies, allowing cross-case comparison and aggregation.

Regarding the quantification of impacts, our aim was to judge and compare impact across cases. Impact intensity is quantified on an ordinal scale from 1 (weak impacts) to 5 (strong impacts). A scoring metric template was established for each impact dimension based on an inter-case comparison. More detailed measurement was performed on impact dimensions where the anticipated ranking exceeded 4 out of 5.

The ASIRPA team, working on finding possible societal impact indicators, developed a ‘conceptual model’ of societal impact (Bozeman \& Kingsley 1997). In 2013 and 2014, work 
was done on the economic, political and environmental dimensions. Translation of quantification values into rankings from 1 to 5 is based on the scoring range built by ASIRPA. For the quantification of the economic impact of each case, we relied on a classical method based on economic surplus calculation (Georghiou \& Roesner 2000; Mansfield 1996) and for which we set standardized parameters: the economic surplus generated over 20 years by each case study is compared to a scoring range proportional to INRA's average annual budget. For the assessment of political impact there is no relevant grid in the literature (see Cozzens \& Snoek 2010; Jones 2009; Kingdon 1984; Lindquist 2001; Weiss 1979 for possible contributions of science to policy). This applies also to environmental impacts (see Hermann et al. 2006 for an attempt of combination of existing approaches). ASIRPA thus referred to expert panels, as suggested in the literature. Based on the literature, we designed a grid subdividing the political impacts along three axes: contribution to public debate, influence on policy-making, and mid-term percolation of ideas in political spheres, weighted by the importance of the policy domain concerned. The grid submitted to the experts on environmental impacts distinguished the impacts in four sub-domains: climate change, biodiversity, pollution, and consumption of resources on a local and global scale. The panels were comprised of external researchers in political and environmental sciences, policy-makers from the French Agriculture and Environment Ministries, and representative from public specialist agencies. The expert panels were responsible for critiquing the relevance of the grid, and after reading the case reports, identifying the most-significant indicators for each of these sub-dimensions.

Quantification of impact is summarized in the impact vector, comprising an impact table and a radar. These visual representations give a picture of the spectrum of impact of each case. They also provide a broad picture of the intensity and diversity of INRA's impact (figure 3), which is one achievement of the scaling-up process described in the next section. 
Figure 3: example of impact radars from ASIRPA case studies
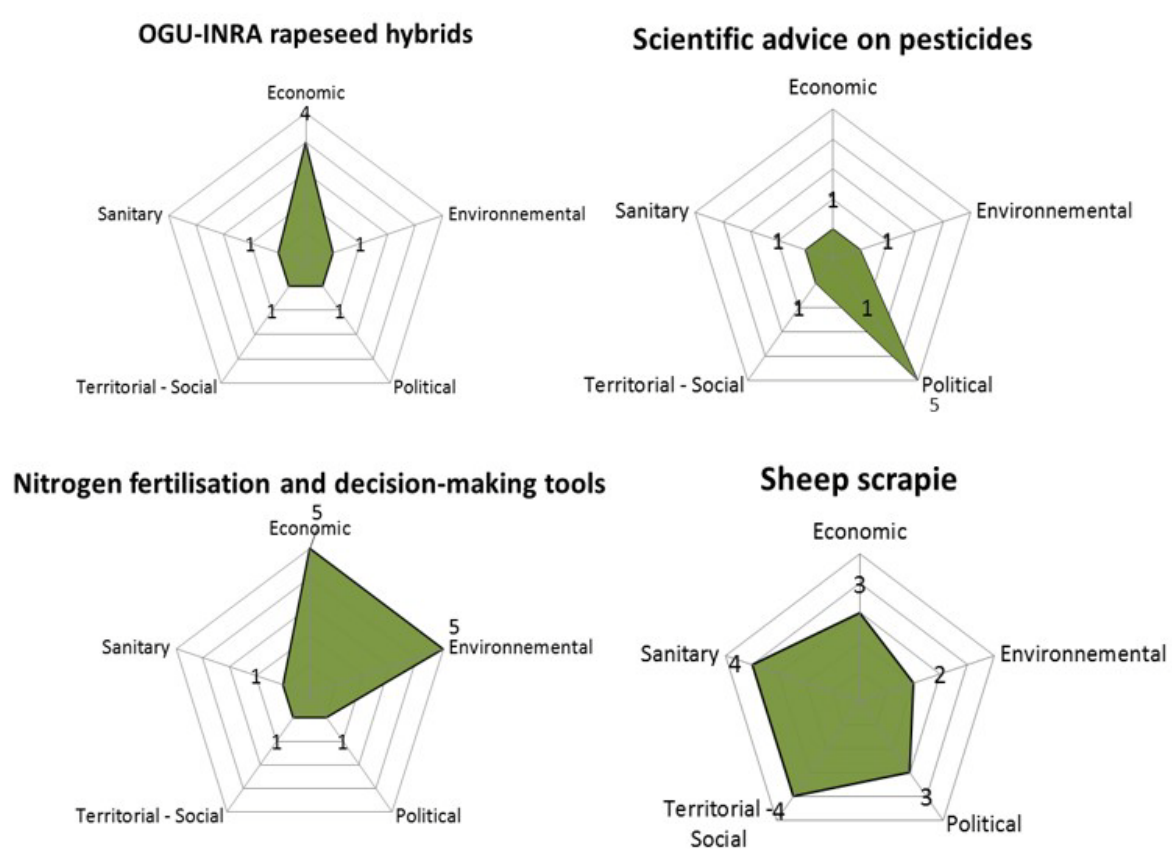

\subsection{Aggregation and scaling-up: analyzing the impact at the level of the organization}

Our objective through the aggregation of cases was to generalize the findings from the case studies to produce robust results on INRA's societal impact and to identify impact-generation.

The aggregation process rests on the design of a database of case studies. This database contains encoded information related to the impact pathway. Its variables were designed during the project, based on the first cases studied. Eventually, a set of 100 variables was coded for each of the 33 cases.

The results will be completed and consolidated by regularly incrementing the case study base. However, the complex selection process we developed, combining the research results database with interviews with heads of departments ensures some representativeness of our sample at the level of the organization.

\subsubsection{Cross-cutting analysis}

Cross-case comparisons offered in the literature aim at aggregating the impacts from case studies (Bozeman \& Sarewitz 2011; Donovan \& Hanney 2011; EMBRAPA 2013; de Jong et 
al. 2014). Even recent initiatives (EMBRAPA 2013) focus on the generalization of data related to impacts. The first objective of ASIRPA through the cross-cutting analysis based on the database of cases is more ambitious. It aims at identifying general characteristics of impact pathways, mechanisms, roles of INRA in the innovation networks, and productive configurations. It enables us to describe the characteristics of the general impact of INRA in terms of its size and dimension but also to identify the conditions required for a pathway to become productive.

Our analysis yielded original results in describing the characteristics of the impact associated with INRA research in terms of size and dimension, but also in identifying the conditions required for a pathway to become productive (see Matt et al., manuscript in preparation). ${ }^{2}$

As far as impact is concerned, they appear to be distributed along the five selected dimensions: $79 \%$ of the cases affect more than one dimension of impact. Impact is mostly economic (53\% of cases), environmental (63\% of cases), and political (53\% of cases), and less often sanitary or territorial-social. Cases that strongly affect the environment often have economic impact, while cases affecting the economy strongly tend to have less political impact. Generalization of impacts 1 often result in their diversification.

Apart from these results strictly related to impact, the ASIRPA cross-cutting analysis yielded much richer findings regarding the impact pathways of INRA:

- The production of impacts is the result of long-term investments in research, and of socioeconomic partnerships for knowledge production. In the cases studied, impacts were produced in those fields where INRA had accumulated competencies over a long period, and where it had a research infrastructure: biological or genetic collections, experimental facilities, etc. (93\% of the cases analysed). Most of the research involved several

\footnotetext{
${ }^{2}$ A typology of impact pathways generated by a public agricultural research organization
} 
disciplines (97\%), and knowledge other than scientific, especially technical knowledge and know-how. The stories identified in the different cases were very long (14 year time-lag on average between research and impacts) but were based on even older competencies and infrastructures.

- In a large majority of cases, INRA has contributed to the production of basic knowledge, with the Institute's researchers often among the scientific leaders in their field internationally. Also, the cases that have generated the strongest impacts have required more applied research producing actionable knowledge. In 73\% of cases, the knowledge was incorporated in technical objects, models, databases, and so on. INRA researchers made contributions of various kinds that helped remove critical barriers along the impact pathway. In $87 \%$ of cases, they were instrumental in structuring actor networks by coordinating research either upstream (e.g. via the creation of consortia) or down i.e. outputs (creation of intermediaries, adaptation of regulations).

- The actor network is regularly transformed during the diffusion of outputs. This shows that the partners who are the most likely to participate in the research phase are not necessarily the best in the other phases of the impact pathway.

\subsubsection{Typological analysis}

The second objective of the cross-cutting analysis is to build a typology of impact pathways highlighting the main mechanisms of each type of pathway. Based on codification of the 33 cases in the database, the typological analysis distinguishes the 11 cases of political impacts in a specific class. The analysis of the other 18 cases is based on two discriminating dimensions: the degree of participation of the non-academic actors in the research phases (co-production of knowledge) and degree of transformation of the environments in which knowledge is used, thus distinguishing four types. 
This typology can be used to better understand the type of impacts produced, the degree of difficulty faced, critical points on the pathway to impact. It is a key tool for learning purposes and management of impact within an organization. It reveals that success depends on the strategies of INRA but also on the characteristics of the socio-economic environment. It also shows that there is not one best pathway to impact, and that approaches which suggest substituting analysis of productive interactions for realized impact miss a very important point. It could be used to monitor the portfolio of impact of INRA, understand the mechanisms and critical conditions or impact generation.

\section{Discussion and conclusion}

\subsection{Methodological forces}

The ASIRPA approach addresses the main methodological barriers highlighted in the relevant literature. It is a comprehensive approach to societal impact that mobilizes state-of-the-art methodological tools as building blocks. Our qualitative case study approach accounts for the complexity involved in the process of impact generation of a wide range of academic research. Our analysis is similar in many respects to the abductive reasoning and qualitative research procedure in Van Maanen et al. (2007). It was conducted as a continuous back-andforth process, relating concepts and data. It enabled us to explore new impact generating mechanisms, new practices, and existing links among the various networks of actors, enrolment, and interessement mechanisms (Callon 1986), and the types of impact generated. The standardized framework we designed and used to conduct these case studies helped overcome classical aggregation difficulties. Quantification of impact partly proceeds from monetary estimation of economic impact as suggested by a number of authors (Evenson 2001; Jaffe 1989 for calculation of rates of return; Georghiou \& Roesner 2000; Ruegg \& Feller 
2003) for a combination of econometric, bibliometric and statistical methods on a case-study basis (Cohen et al. (2002); Klevorick et al. (1995); Mansfield (1998); Salter \& Martin (2001)). The ASIRPA approach also developed a proper scoring grid to convert qualitative local descriptors into general indicators of political, social, territorial, sanitary, and environmental impacts and to finally quantify each impact dimension on a 1 to 5 scale. This is a step forward since non-economic impact indicators are mostly underdeveloped (with the exception of TOE for energy and $\mathrm{CO}_{2}$ emissions for climate change), and a large amount of work remains to be done to consolidate existing approaches. The methodology used by ASIRPA, following a suggestion from Ruegg and Feller (2003) to consult expert panels to build the political and environmental grids, has contributed to the objectification and robustness of impact measurement.

The methodological choice to consider a vector of societal impacts refers to the public values of research, accurately identified by Bozeman and Sarewitz (2011), who underline their theoretical and political breadth. The branches of the vector are closely related to the diversity of the benefits of research resulting from the PRO’s missions and societal expectations.

Georghiou and Roesner (2000) argue that a methodology chosen to assess impacts needs to match the objectives of the evaluation process: either 'learning and adaptation', or ‘compliance and accountability’ (Guijt 2000, p. 216), or respond to stakeholders’ requests. Qualitative methods are usually more adapted to learning objectives while quantitative ones better fit accountability objectives. Responding to the diversity of stakeholders' requests requires ad hoc methods, often requiring the combination of qualitative and quantitative tools. Overall, the ASIRPA approach qualitatively and quantitatively accounts for impacts while also considering the long delay before impact, and explaining the related impact generation processes. It is adapted to the various objectives pursued by PROs worldwide, particularly those specialized in agriculture. 
The objective of the ASIRPA approach is to learn about impact generating mechanisms rather than to account solely for the societal efficiency of research investments. Thus, it abandons the goal of isolating the effects of particular investments, and leads to a series of strong methodological positions to bypass attribution and project fallacy matters. Results from our cross-case analysis (Matt et al., manuscript in preparation) reveal that researchers often engage in the downstream valorization of research. Thus, the methodological investment made via ASIRPA in contribution and network analysis is worthwhile. Contribution analysis (Mayne 2001) is a liberating approach that raises original analytical and strategic questions related to the credibility of the contribution story (Lemire et al. 2012), typical productive configurations, and the mechanisms at stake.

\subsection{Implementation advantages}

Above all, ASIRPA has proven usable on a day-to-day basis. Its implementation on 33 case studies proved the approach was sufficiently generic to account for various impact configurations, while also sufficiently robust and detailed to allow for a sensitive cross-case and typological analysis. Its successful transfer to half of INRA's 14 scientific departments demonstrates that it was 'not too labour intensive' and was 'economically viable', as recommended by Frank and Nason (2009, p. 531). Over 40 INRA principal investigators and technology transfer officers have been taught to process case studies following the ASIRPA standard. The three standardized tools (impact pathway, chronology, and vector of impacts), and the report template, facilitate the portability of the methodology. These tools, inspired by the international literature on PROs are neither country-specific nor agriculture-specific. Our generic and normalized approach could be adapted for broad external use by other PROs. Using scientifically approved tools as building blocks, it contributes to the creation of a global standard by increasing the degree of normalization across existing methodologies. Bornmann 
(2013, p. 220) argues for normalization since it allows 'for different research institutes to be comparable in the context of societal impact measurement'.

The usefulness to INRA of such an approach is based on several aspects. It demonstrates the high societal impact of outputs such as scientific advice or biobanks whose contribution is often neglected since it is difficult to isolate. The collection of case studies produced by principal investigators is also powerful for research team members' self-motivation (particularly technicians), and external communication purposes. As suggested by Raina (2003), such practices may enable a shared view of the evaluation inside INRA, thus producing institutional learning. It is a ready-to-use database of proofs of the societal utility of the organization in a variety of economic sectors. We have already witnessed advantages in terms of learning on impact generating mechanisms, and the adoption of good practice.

\subsection{Conclusion}

Methodologies to evaluate the impact of research institutes are evolving. Values attached to agricultural research are also evolving: the focus on productivity has been complemented by social concerns about the environment, food and society, and global issues. ASIRPA develops a framework that is scientifically robust, credible, and relevant for stakeholders. It has been built to answer the need for new methodologies based on existing methodological features.

\section{References}

Acil Tasman Pty Ltd. (2010). Assessment of CSIRO impact and value, p. 76. Melbourne: CSIRO.

Alston, J. M., Pardey, P. G., James, J. S., \& Andersen, M. A. (2009). The Economics of Agricultural R\&D. Annual Review of Resource Economics, 1: 537-65.

Arrow, K. J. (1962). The Economic Implications of Learning by Doing. Review of Economic Studies, 29: 155-73.

Bell, S., Shaw, B., \& Boaz, A. (2011). Real-world approaches to assessing the impact of environmental research on policy. Research evaluation, 20/3: 227-37.

Bijker, W. (1995). Of Bicycles, Bakelites, and Bulbs: Toward a Theory of Socio-Technical Change. Cambridge, MA: MIT Press. 
Bornmann, L. (2013). What is societal impact of research and how can it be assessed? a literature survey. Journal of the American Society for Information Science and Technology, 64/2: 217-33.

Bozeman, B. (2003). Public Value Mapping of Science Outcomes: Theory and Method. D. Sarewitz, et. al. Knowledge Flows \& Knowledge Collectives: Understanding the Role of Science \& Technology Policies in Development, 2, Vol. 1.

Bozeman, B., \& Kingsley, G. (1997). R\&D value mapping: A new approach to case studybased evaluation. The Journal of Technology Transfer, 22/2: 33-41.

Bozeman, B., \& Melkers, J. (1993). Evaluating R\&D impacts: Methods and practice. Springer.

Bozeman, B., \& Sarewitz, D. (2011). Public Value Mapping and Science Policy Evaluation. Minerva, 49: 1-23.

Buxton, M. (2011). The payback of 'Payback': challenges in assessing research impact. Research Evaluation, 20/3: 259-60.

Callon, M. (1986). The sociology of an actor-network. Mapping the Dynamics of Science and Technology, Macmillan. M. Callon, J. Law, and A. Rip: London.

- (1992). The Dynamics of Techno-economic Networks. Technical Change and Company Strategies, Academic Press, pp. 73-102. Coombs R., Saviotti P., Walsh V.: London.

Campbell, \& al. (2010). Assessment of CSIRO, impact and value. Economics Policy Strategy, ACIL Tasman.

Chesbrough, H. (2006). Open Innovation, the New Imperative for Creating and Profiting from Technology, Harvard Business School Press W.

Cohen, W. M., Nelson, R. R., \& Walsh, J. (2002). Links and impacts: the influence of public research on industrial R\&D. Management Science, 48/1: 1-23.

Colinet, L., Gaunand, A., Joly, P.-B., Lemarié, P., Matt, M., Larédo, P., \& Hocdé, A. (2013). Une approche multidimensionnelle de la mesure des effets de la recherche publique agronomique: le cas de l'INRA. Penser la valeur d'usage des sciences. Olivier Glassey, Jean-Philippe Leresche et Olivier Moeschler: Université de Lausanne.

Cozzens, S., \& Snoek, M. (2010). Knowledge to Policy Contributing to the Measurement of Social, Health, and Environmental Benefits. Presented at the Workshop on the Science of Science Measurement, December 2, Washington, DC.

Cunningham, P., Gök, A., \& Laredo, P. (2013). The Impact of Direct Support to R\&D and Innovation in Firms (Nesta Working Paper No. 13/03). Manchester: MIOIR-NESTA compendium of evidence on the effectiveness of innovation policy intervention.

Donovan, C. (2011). State of the art of assessing research impact: introduction to a special issue, Research Evaluation. Research Evaluation, 20/3: 175-9.

Donovan, C., Butler, L., Butt, A. J., Jones, T. H., \& Hanney, S. R. (2014). Evaluation of the impact of National Breast Cancer Foundation-funded research. The Medical Journal of Australia, 200/4: 214-8.

Donovan, C., \& Hanney, S. (2011). The 'Payback Framework' explained. Research Evaluation, 20/3: 181-3.

Douthwaite, B., Kuby, T., van de Fliert, E., \& Schulz, S. (2003). Impact pathway evaluation: an approach for achieving and attributing impact in complex systems. Learning for the future: Innovative approaches to evaluating agricultural research, 78/2: 243-65.

EMBRAPA. (2013). EMBRAPA's Social Report 2012. Brasilia: Distrito Federal (DF): Embrapa, Communication Secretariat, Strategic Management Secretariat.

Ernø-Kjølhede, E., \& Hansson, F. (2011). Measuring research performance during a changing relationship between science and society. Research Evaluation, 20/2: 131-43. 
Evenson, E. (2001). Economic impacts of agricultural research and extension. in Gardner, R.E. and Rausser, G.Handbook of Agricultural Economics, vol 1A, Elsevier., pp. 573628.

Frank, C., \& Nason, E. (2009). Health research: measuring the social, health and economic benefits. Canadian Medical Association Journal, 180/5: 528-34.

Gaunand, A., Hocdé, A., Lemarié, S., Matt, M., \& De Turckheim, E. (2015). How does public agricultural research impact society? A characterization of various patterns. Research Policy, 44: 849-61.

Georghiou, L. (1999). Socio-economic effects of collaborative R\&D—European experiences. The Journal of Technology Transfer, 24/1: 69-79.

- (2007). What lies beneath: Avoiding the risk of under-evaluation. Science and Public Policy, 34/10: 743-52.

Georghiou, L., \& Bach, L. (1998). The nature and scope of RTD impact measurement. Presented at the International Workshop on Measurement of RTD Results/Impact.

Georghiou, L., \& Clarisse, B. (2006). Introduction and Synthesis, in Government R\&D Funding and Company Behaviour. Measuring Behavioural additionality, p. 243. OECD.

Georghiou, L., Rigby, J., Cameron, H., Vonortas, N., Prastacos, G., Spanos, Y., Kuhlmann, S., et al. (2002). Assessing the Socio-economic Impacts of the Framework Programme, p. 368. Manchester: PREST.

Georghiou, L., \& Roesner, D. (2000). Evaluating technology programs: tools and methods. Research Policy, 29: 657-78.

Godin, B., \& Doré, C. (2005). Measuring the Impacts of Science; Beyond the Economic Dimension. Presented at the Urbanisation INRS, Culture et Société. Helsinki, Finland: Helsinki Institute for Science and Technology Studies.

Green, K., Hull, R., McMeekin, A., \& Walsh, V. (1999). The construction of the technoeconomic: networks vs. paradigms. Research Policy, 28/7: 777-92.

Griliches, Z. (1958). Research costs and social returns: hybrid corn and related innovations. The Journal of Political Econnomy, 66/5: 419-31.

Guijt, I. (2000). Methodological issues of participatory monitoring and evaluation. Learning from Change-Issues and Experiences in Participatory Monitoring and Evaluation, IDRC/ ITP, pp. 201-16. Estrealla, M.: London.

Hanney, S., Grant, J., Wooding, S., \& Buxton, M. (2004). Proposed methods for reviewing the outcomes of health research: the impact of funding by the UK's 'Arthritis Research Campaign'. Health Research Policy and Systems, 2/1: 4.

Hermann, B., Kroeze, C., \& Jawjit, W. (2006). Assessing environmental performance by combining life cycle assessment, multi-criteria analysis and environmental performance indicators. Journal of Cleaner Production, 1-10.

Jaffe, A. (1989). Real effects of academic research. American Economic Review, 79: 957-70.

Jones, H. (2009). Policy-making as discourse: a review of recent knowledge-to-policy literature. ODI-IKM Working Papers, 5: 37.

De Jong, S., Barker, K., Cox, D., Sveinsdottir, T., \& Van den Besselaar, P. (2014). Understanding societal impact through productive interactions: ICT research as a case. Research Evaluation, 23/2: 89-102.

Kamenetzky, J. R. (2013). Opportunities for impact: Statistical analysis of the National Science Foundation's broader impacts criterion. Science and Public Policy, 40: 72-84.

Kingdon, J . (1984). Bridging Research and Policy: Agendas, Alternatives, and Public Policies, New-York: Harper Collins. New-York: Longman. 
Klerkx, L., \& Aarts, N. (2013). The interaction of multiple champions in orchestrating innovation networks: Conflicts and complementarities. Technovation, 33/6-7: 193210.

Klevorick, A., Levin, R., Nelson, R. R., \& Winter, S. (1995). On the sources and significance of inter-industry differences in technological opportunities. Research Policy, 24/2: 195-205.

Kuby, T. (1999). Innovation as a Social Process: What Does this Mean for Impact Assessment in Agricultural Research. Presented at the CIAT worksop, September, Costa Rica.

Lemire, S. T., Nielsen, S. B., \& Dybdal, L. (2012). Making contribution analysis work: A practical framework for handling influencing factors and alternative explanations. Evaluation, 18/3: 294-309.

Lindquist, E. (2001). Discerning Policy Influence: Framework for a Strategic Evaluation of IDRC-Supported Research. Presented at the Cases, Concepts and Connectionthe Influence of Research on Public Policy; Evaluation Workshop, Ottawa, ON, CA: School of Public Administration University of Victoria.

Van Maanen, J., Sorensen, J. B., \& Mitchell, T. R. (2007). Intrdoction to special tpic forum. The interplay between theory and method. Academy of Management Review, 32/4: 1145-54.

Mansfield, E. (1996). Estimating Social and Private Returns from Innovations Based on the Advanced Technology Program: Problems and Opportunities. University of Pennsylvania. NIST CGR.

- (1998). Academic research and industrial innovation: an update of empirical findings. Research Policy, 26: 773-6.

Maredia, M. K., \& Raitzer, D. A. (2006). CGIAR and NARS partner research in sub-Saharan Africa: evidence of impact to date. Science Council Secretariat.

- (2012). Review and analysis of documented patterns of agricultural research impacts in Southeast Asia. Agricultural Systems, 106/1: 46-58.

Mayne, J. (2001). Addressing attribution through contribution analysis: using performance measures sensibly. Canadian journal of program evaluation.

(2012). Contribution analysis: Coming of age? Evaluation, 18/3: 270-80.

Molas-Gallart, J., Salter, A., Patel, P., Scott, A., \& Duran, X. (2002). Measuring third stream activities (Final Report to the Russell Group of Universities). Science and Policy Research Unit, University of Sussex.

Molas-Gallart, J., \& Tang, P. (2011). Tracing 'productive interactions' to identify social impacts: an example from the social sciences. Research Evaluation, 20/3: 219-26.

Nason, E., \& al. (2011). Evaluating health research funding in Ireland: assessing the impacts of the Health Research Board of Ireland's funding activities. Research Evaluation, 20/3: 193-200.

Nedeva, M. (2013). Between the global and the national: Organising European science. Research Policy, 42/1: 220-30.

Nelson, R. (1959). The Simple Economics of Basic Scientific Research. Journal of Political Economy, 67: 297-306.

Nightingale, P. (2004). Technological capabilities, invisible infrastructure and the un-social construction of predictability: the overlooked fixed costs of useful research. What do we know Innovation? Selected papers from an International Conference in honour of Keith Pavitt, 33/9: 1259-84.

Pascucci, S., \& de-Magistris, T. (2011). The effects of changing regional Agricultural Knowledge and Innovation System on Italian farmers' strategies. Agricultural Systems, 104/9: 746-54. 
Poppe, K. J. (2008). Economic assessment of Dutch agricultural research ( No. 2008_-032). Wageningen: LEI Wageningen UR.

Raina, R. S. (2003). Disciplines, institutions and organizations: impact assessments in context. Learning for the future: Innovative approaches to evaluating agricultural research, 78/2: 185-211.

Research Evaluation Framework. (2011). Descisions on assessing research impact ( No. REF 01.2011). Northavon House Coldharbour Lane Bristol BS16 1QD.

Ruegg, R., \& Feller, I. (2003). A Toolkit for Evaluating Public R\&D Investment: Models, Methods, and Findings from ATP's First Decade. (Grant/Contract Report). Gaithersburg: National Institute of Standards and Technology.

Ruegg, R., \& Jordan, G. (2007). Overview of evaluation methods for R\&D programs: A Directory of Evaluation Methods Relevant to Technology Development Programs. US Department of Energy.

Salter, A., \& Martin, B. R. (2001). The economic benefits of publicly funded basic research: a critical review. Research Policy, 30/3: 509-32.

Scherer, F. ., \& Harhoff, D. (2000). Technology policy for a world of skew-distributed outcomes. Research Policy, 29/4-5: 559-66.

Spaapen, J. M., \& Van Drooge, L. (2011). Introducing 'productive interactions' in social assessment. Research Evaluation, 20/3: 211-8.

Suh, J., \& MacPherson, A. (2007). The impact of geographical indication on the revitalisation of a regional economy: a case study of 'Boseong' green tea. Area, 39/4: 518-27.

Walker, T., Maredia, M., Kelley, T., Rovere, R. L., Templeton, D., Thiele, G., \& Douthwaite, B. (2008). Strategic Guidance for Ex Post Impact Assessment of Agricultural Research. Science Council Secretariat: Rome, Italy: Report prepared for the Standing Panel on Impact Assessment, CGIAR Science Council.

Weiss, C. H. (1979). The Many Meanings of Research Utilization. Public Administration Review, 39/5: 426-31. 